\title{
Determination of the Effectiveness of Hal Bark (Vateria copallifera) as a Natural Preservative for Food Security of Confectionery Industry
}

\author{
S.B. Navaratne * \\ Department of Food Science and Technology, University of Sri Jayewardenepura, Sri Lanka
}

Date Received: 25-11-2015 Date Accepted: 05-12-2015

\begin{abstract}
Hal (Vateria copallifera) bark can be used to control sugar fermentation process by yeast. Therefore, it was subjected to sun, mechanical, shade and cooling with dehumidified (CD) drying processes in order to identify the best drying method. $1.5 \mathrm{~g}$ of dried bark from four drying processes were introduced into four, $40 \%$ sugar (sucrose) solutions to identify the best drying method in terms of froth formation. In addition, $1.5 \mathrm{~g}$ of hal bark was introduced into 30\%, 40\%, 50\% and $60 \%$ sugar solutions to determine at what sugar concentration that hal bark is capable to control sugar fermentation. Moreover, 0.5, 1.0, 1.5, 2.0 and $3.0 \mathrm{~g}$ of bark from the best drying method were introduced into 50\% sucrose solutions to determine the level that Hal bark can be incorporated into sugar solutions without changing the sugar taste. Finally, optimum level of Hal bark was introduced into 50\% sugar solution and levels of reducing, non-reducing and total sugars against the control were monitored. Sugar solutions were inoculated with $1.0 \%$ yeast.
\end{abstract}

The best drying method was $\mathrm{CD}$ as it was capable to control sugar fermentation at $40 \%$ sugar level and others had it at $50 \%$ level. Sensory evaluation revealed that up to $1.0 \mathrm{~g}$ of hal bark can be incorporated into $100 \mathrm{ml}$ of sugar solutions without disturbing to the sugar taste. While $1 \mathrm{~g}$ of hal bark was capable to control sugar fermentation at 50\% sugar level, control had same performance at $60 \%$. $1.2 \mathrm{~g}$ of Hal bark from the best drying method in $50 \%$ sugar solution was capable to maintain reducing, non-reducing and total sugars unchanged against the control.

Keywords: Vateria copallifera, copalliferol, reducing sugar, non-reducing sugar, hal bark

\section{Introduction}

Hal (Vateria copallifera) tree is native to Sri Lanka and its bark has been used for long time by rural folk in some areas of the country as an age old practice to prevent sugar-yeast fermentation process in treacle (Dassanayaka and Forberg, 1980). As this plant is widely available in the natural habitats of south west region, particularly on the hill sides and the river banks of the country, peasants in these areas incorporate a small piece of this bark to the treacle just after accomplishment of the boiling process of the sap water of Kitul (Caryota urens) or Coconut (Cocos nucifera) (Kostermans, 1982). As yeast govern fermentation process of the treacle badly affecting to its keeping quality as well as to its organoleptic properties, the domestic scale producers have discovered that hal bark is the ideal

*Correspondence: sbnava@sci.sjp.ac.lk

Tel: +94-77-509-5610

ISSN 2235-9370 Print/ISSN 2235-9362 Online (C University of Sri Jayewardenepura 
solution to control the sugar fermentation process (Ratnasooria et al., 2006), that negatively perceived by the consumers in the dynamic market. Since sugar fermentation process is carried out by the yeast, it is capable to produce different kind of enzymes to convert carbohydrates into sugars and thereafter into alcohol, carbon dioxide and energy (Swaminathan, 1988). Therefore, it can be presumed that water soluble chemical components in hal bark may be able to either kill the microorganisms or convert them dormant or defunct or destroying the enzymes they produced during the process of sugar fermentation.

Therefore, a study was conducted to evaluate the scientific background of the hal bark against the sugar fermentation process as well to find out an appropriate drying method to preserve antiseptic chemical components of it.

\section{Methodology}

\subsection{Determination of the best drying method in drying of hal bark}

$2 \mathrm{~kg}$ of fresh Hal bark were taken and cut into small pieces $(2 \times 2 \mathrm{~cm})$ using a stainless steel knife. Thereafter, these pieces were divided into four equal portions and each portion was dried in the sun for $72 \mathrm{hrs}$, under shade for $12 \mathrm{hrs,} \mathrm{in} \mathrm{a} \mathrm{mechanical} \mathrm{dryer} \mathrm{(sensible} \mathrm{heating} \mathrm{at} \mathrm{constant} \mathrm{humidity}$ ratio at $75-80^{\circ} \mathrm{C}$ ) for $36 \mathrm{hrs}$ and in a cooling with a dehumidifying dryer at $6-8^{\circ} \mathrm{C}$ for $96 \mathrm{hrs}$ until moisture content reached to 6-8\%. Thereafter, $1.5 \mathrm{~g}$ of dried hal bark from each treatment was introduced into $100 \mathrm{ml}$ of $40 \%$ sugar (Sucrose) solution along with $1.0 \mathrm{~g}$ of compressed yeast. Finally, efficacy of each drying process was monitored in terms of volume of froth formation within 20 minutes time. Three replicates were used for all treatments.

\subsection{Determination of desirable amount of Hal bark that can be incorporated into a sugar solution}

Dried hal bark obtained from the best drying process was subjected for this study. Therein, 0.5 , $1.0,1.5,2.0$ and $3.0 \mathrm{~g}$ of dried hal bark were introduced into $100 \mathrm{ml}$ of $50 \%$ sucrose solutions with the view to determine up to which level that the hal bark can be incorporated into a sugar solution without disturbing to its sugar taste (sweet taste). Thereafter, 10 numbers of trained sensory panellists were asked to taste the sensory stimulus sweetness of each sugar solution and to indicate the level that Hal bark can disturb the sugar taste sensoraly. Three replicates were used for all treatments.

\subsection{Determination of desirable sugar concentration that Hal bark can prevent sugar-yeast fermentation}

Four sugar solutions at 30\%, 40\%, 50\% and 60\% concentrations were taken and introduced into $100 \mathrm{ml}$ measuring cylinders up to $80 \mathrm{ml}$ and then $1.5 \mathrm{~g}$ of dried hal bark from the best drying process along with $0.8 \mathrm{~g}$ of compressed yeast was introduced. All treatments were kept at the same environmental condition $\left(30^{\circ} \mathrm{C}, \mathrm{RH} 70 \%\right)$ for 30 minutes. Thereafter, these four treatments were allowed for fermenting and height of the froth formed was measured. All treatments were replicated thrice and mean value of the height of the froth formed were used to plot a graph sugar concentration verses height of the froth. The same procedure was adapted to same sugar concentrations without incorporation of Hal bark as a control treatment.

\subsection{Determination reducing, non-reducing and total sugars of a Hal bark treated sugar solution}

Best amount of hal bark (1.0 $\mathrm{g}$ for $100 \mathrm{ml}$ of sugar solutions) that did not disturb the sugar taste sensoraly was taken from the best drying process and introduced into 50\% sugar solution along with $1.0 \mathrm{~g}$ of compressed yeast. Thereafter, the treatment was allowed for fermentation for 30 minutes and fermented solution was used in determining of total sugar, reducing sugar, and non reducing sugar. The trial was replicated thrice and mean value of them were taken to interpret the results. Same procedure 
was adapted to $50 \%$ sugar solution without incorporation of $1.0 \mathrm{~g}$ hal bark as a control treatment while replicating all treatments thrice.

\subsection{Determination of total sugar}

$5 \mathrm{~g}$ of sugar was measured into a conical flask and distilled water was added up to $250 \mathrm{ml}$ in order to prepare a standard sugar solution. $25 \mathrm{ml}$ from the prepared solution was taken into a beaker and $15 \mathrm{ml}$ of $1 \mathrm{~N}$ concentrated hydrochloric acid and about $10 \mathrm{ml}$ distilled water were added. The flask was kept at $70^{\circ} \mathrm{C}$ for $10 \mathrm{~min}$ in a water bath, cooled immediately and neutralized with $10 \% \mathrm{NaOH}$ along with 2-3 drops of phenolphthalein indicator. The neutralised invert solution was transferred quantitatively into a graduated flask and made up the volume to $200 \mathrm{ml}$. Portion of the solution was poured into a $50 \mathrm{ml}$ burette. $10 \mathrm{ml}$ of Fehling's A and B mixed solution with few drops of Methylene blue was put into a $300 \mathrm{ml}$ of conical flask and titrated against the burette solution while boiling until solution reach brick red.

$$
\text { Total sugar }=\frac{200 \times 50.2}{V_{2} \times W}
$$

where:

$$
\begin{aligned}
& \mathrm{V}_{2}=\text { Titrated volume, } \mathrm{ml} \\
& \mathrm{W}=\text { Weight of sugar, } \mathrm{g}
\end{aligned}
$$

\subsection{Determination of reducing sugar}

Standard sugar solution ( $5 \mathrm{~g}$ of sugar dissolved in $250 \mathrm{ml}$ of distilled water) was put into a 50 $\mathrm{ml}$ burette. $10 \mathrm{ml}$ of Fehling's A and B mixed $(5 \mathrm{ml}$ each) solution was put into a $300 \mathrm{ml}$ conical flask and gently boiled the contents in the flask for two minutes. At the end of $2 \mathrm{~min}$ of boiling, $1 \mathrm{ml}$ of methylene blue indicator was added into the solution without interrupting boiling. While content of the flask continued to boil, started adding the prepared solution from the burette till the blue colour of the indicator just disappears.

$$
\text { Reducing sugar }=\frac{50.2 \times 25}{V_{1} \times W}
$$

where:

$$
\mathrm{V}_{1}=\text { Titrated volume, } \mathrm{ml}
$$

\section{Determination of non-reducing sugar}

Non-reducing sugar was calculated by subtracting the amount of reducing sugar from the amount of total sugar.

\section{Results}

\subsection{Determination of the best drying method in drying of hal bark}

Table 1: Method of drying vs. volume of froth formation in sugar solutions.

\begin{tabular}{lcccc}
\hline Method of drying & \multicolumn{4}{c}{ Volume of froth in 3 replicates (ml) } \\
\cline { 2 - 5 } & 1 & 2 & 3 & Mean volume \\
\hline Sun drying & 1.0 & 1.2 & 0.8 & 1.0 \\
Shade drying & 0.2 & 0.0 & 0.1 & 0.1 \\
Mechanical drying & 2.0 & 1.8 & 2.0 & 1.9 \\
Cooling with dehumidified drying & 0.0 & 0.0 & 0.0 & 0.0 \\
\hline
\end{tabular}




\subsection{Determination of desirable amount of hal bark that can be incorporated into sugar solutions}

The actual threshold level of hal bark (the quantity of hal bark needed to detect hal taste in sugar solutions) in a 50\% sugar solution was determined by using 10 members trained sensory panel according to the method described by Stone and Sidel (1985). Results are given in the Table 2.

Table 2: Actual thresh hold level of hal bark in a 50\% sugar solution.

\begin{tabular}{cl}
\hline Amount of hal bark $(\mathrm{g})$ & Test Result \\
\hline 0.5 & Not noticeable \\
1.0 & Not noticeable \\
1.5 & Slightly noticeable \\
2.0 & noticeable \\
3.0 & noticeable and disturbing to the sugar taste \\
\hline
\end{tabular}

3.3 Determination of desirable sugar concentration that hal bark can prevent sugar-yeast fermentation

The height of the froth formation of sugar solutions at $20 \%, 30 \%, 40 \%, 50 \%$, and $60 \%$ concentrations with and without hal bark were measured and results are depicting in the Figure 1.

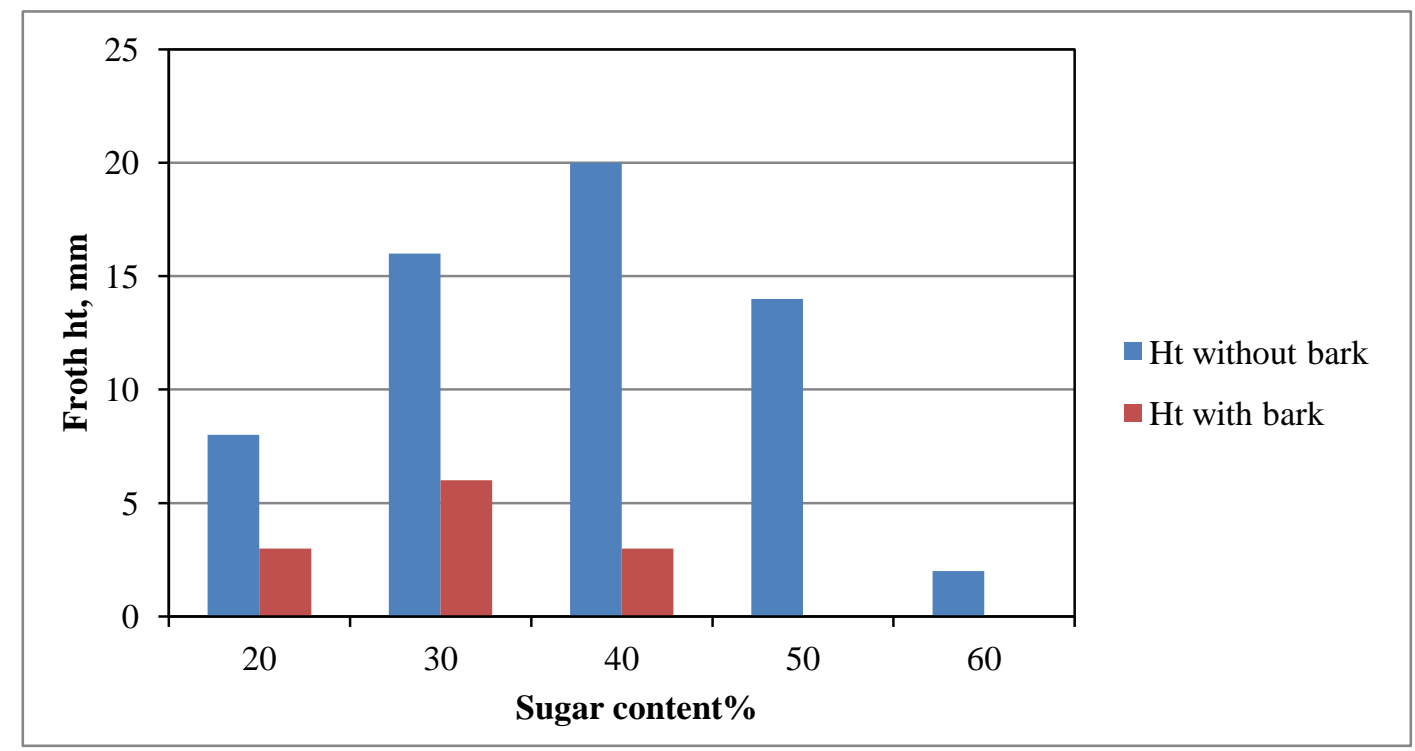

Figure 1: Sugar concentration versus height of the froth

\subsection{Determination of reducing, non-reducing and total sugars of hal a bark treated sugar solution}

Occurring in reducing sugar, non reducing sugar and total sugar were analysed in 50\% sugar solutions, treated with and without hal bark. Results are given in (Table 3). 
Table 3: Changes occurring in reducing sugar, non reducing sugar and total sugar of sugar solutions treated with and without hal bark.

\begin{tabular}{|c|c|c|c|c|c|c|}
\hline \multirow{2}{*}{$\begin{array}{l}\text { Fermentation } \\
\text { time (min) }\end{array}$} & \multicolumn{3}{|c|}{ Without Hal bark } & \multicolumn{3}{|c|}{ With Hal bark } \\
\hline & $\begin{array}{l}\text { Reducing } \\
\text { sugar \% }\end{array}$ & $\begin{array}{c}\text { Non-reducing } \\
\text { sugar } \%\end{array}$ & $\begin{array}{c}\text { Total } \\
\text { sugar } \%\end{array}$ & $\begin{array}{c}\text { Reducing } \\
\text { sugar \% }\end{array}$ & $\begin{array}{l}\text { Non reducing } \\
\text { sugar } \%\end{array}$ & $\begin{array}{c}\text { Total } \\
\text { sugar \% }\end{array}$ \\
\hline 00 & 0.5 & 46.5 & 47.0 & 0.5 & 46.5 & 47.0 \\
\hline 10 & 1.5 & 44.0 & 45.5 & 0.7 & 46.2 & 46.9 \\
\hline 20 & 4.5 & 37.7 & 42.2 & 0.8 & 46.0 & 46.8 \\
\hline 30 & 11.0 & 29.8 & 40.8 & 1.1 & 45.8 & 46.9 \\
\hline 40 & 16.6 & 20.8 & 37.4 & 1.2 & 45.5 & 46.7 \\
\hline 50 & 21.4 & 13.1 & 34.5 & 1.2 & 45.5 & 46.7 \\
\hline
\end{tabular}

\section{Discussion}

Cooling with dehumidified drying process is capable to suppress sugar fermentation process remarkably in compared to the other treatments, especially with fresh and oven dried hal bark. As fresh hal bark contains more water (About 30-35\%) rather than having more antiseptic chemical components, its effectiveness in controlling of sugar fermentation process is less. In the case of oven dried hal bark, effectiveness is relatively less because, high temperature available in the drying air may cause for destroying or vaporisation of the chemical components important for antiseptic properties in prevention of sugar-yeast fermentation process (Champion College of Agriculture, 1984). Therefore, cooling with dehumidified drying process is the best drying method in order to preserve antiseptic properties of the Hal bark because low temperature $\left(6-8^{\circ} \mathrm{C}\right)$ and low water vapour pressure of the cold air are capable to dry the hal bark properly without disturbing to its antiseptic chemical components. However, sun drying and shade drying are also productive options in drying of hal bark, because relatively low drying temperature of these drying processors are also capable to preserve antiseptic properties of the hal bark. Same view has been expressed by Rahman (1980).

Even though the hal bark is an appropriate source for controlling of sugar-yeast fermentation process, bitterness of the bark is severely affecting the sensory stimulus "the sugar taste "of the sugar solution. Thus detection of the sensoraly acceptable level of hal bark to be incorporated into sugar solutions as well as that level is to be capable to control yeast fermentation process are important. Hence, $1 \mathrm{~g}$ of dried hal bark for a $100 \mathrm{ml}$ of sugar solution is the ideal amount in prevention of yeastsugar fermentation process as well as not disturbing to the sugar taste of the sugar solution.

Hal bark is capable to control "sugar-yeast fermentation process" completely when sugar concentration remained $50 \%$ or above with $1 \%$ hal bark. However, same performance was shown by the control treatment at $60 \%$ sugar concentration due to high osmosis pressure of the sugar solution itself. Therefore, ability of hal bark in controlling of sugar fermentation process is depending on a range between $50 \%$ to $60 \%$, because naturally $60 \%$ or above sugar concentrations are capable to control yeast-sugar fermentation process completely due to high osmosis pressure of the sugar concentration (Stanley and Linda, 1988). Hence, hal bark can be used as a preventive treatment in controlling of the growth of yeast in high concentrated sugar solutions rather than controlling of sugar yeast fermentation process in low sugar solutions including trickles too. 
The treatment used as "without hal bark" clearly indicated that total sugar content is steadily declining over the time, because living yeast cells utilise the sugar in order to carry out their metabolic activities.

$$
\mathrm{C}_{6} \mathrm{H}_{12} \mathrm{O}_{5} \longrightarrow \mathrm{CO}_{2}+\mathrm{CH}_{3} \mathrm{CH}_{2} \mathrm{OH}+\text { Energy }
$$

Declining of the sugar content is caused by the production of alcohol and liberation of $\mathrm{CO}_{2}$ as a by product during the sugar-yeast fermentation process (Norman and James, 1977). In the case of declining of non-reducing sugar and increment of reducing sugar are caused by the breakdown of the sucrose into glucose and fructose units by the invertase enzyme secrets by the yeast cells (Cason et al., 1987) as given below.

Sucrose $\underset{\text { Invertase enzyme }}{\longrightarrow}$ Glucose + Fructose

Just after detachment of the glucose and fructose units from the sucrose, these simple sugar units remained in ring form. As long as these individual glucose and fructose units remained in ring form, which is called as non reducing state of the sugar. However, soon after liberation of these individual glucose and fructose units (in ring structure), hydrolysed into straight form which is called reducing state of the sugar. When simple sugars are converted into reducing state, the yeast cells are capable to use these sugars for their metabolic activities.

The treatment incorporated with hal bark, contained two important chemicals, namely Copalliferol A and B, which are capable to prohibit growth of yeast in the sugar solution. Hence, hal bark incorporated sugar solution did not show increment or decrement of total sugar, non-reducing sugar and reducing sugar significantly comparatively controlled treatment.

\section{Conclusion}

Cooling with dehumidified drying method is the most effective drying method to preserve anti microbial properties of hal bark. The desirable amount of hal bark and sugar concentration in controlling of sugar yeast fermentation process are $1.0 \mathrm{~g}$ and $50 \%$ respectively. Using more than $1.0 \mathrm{~g}$ of hal bark into sugar solutions disturbs the sugar taste because of somewhat bitter taste of hal bark. Hal bark is capable to maintain reducing sugar, non-reducing sugar and total sugar in $50 \%$ or more concentrated sugar solutions. Finally, hal bark can be used in controlling of fermentation process of concentrated sugar solutions, including trickle too.

\section{References}

Cason, D.T., Reid, G.C. and Gatner, E.M.S. 1987. On the differing rates of fructose and glucose utilisation in Saccha-romyces eerevisiae. Journal of Industrial Brewery, 93: 23-25.

Cauvain, S.P. and Young, L.S. 1988. Technology of bread making. Campden and Chorleywood Food Research Association, Gloucestershire, UK. Published by Blackie Academic and Professional, London, UK.

Champion college of Agriculture.1984. (Coperative Extension Service Circular 1127), in Drying Food.

Dassanayake, M.D. and Fosberg, F.R. 1980. A revised hand book to the flora of Sri Lanka. Smithsonian Institution and the National Science Foundation, American Publishing Co. Pvt. Ltd. 581.9(548.7).

Desrosier, N.W. and Desrosier, J.N. 1977. The technology of food preservation (4 ${ }^{\text {th }}$ edition). CBS Publishers and Distributers, Delhi, India. 
Kostermans, A.J.G.H. 1982. A hand book of the Dipterocarpaceae of Sri Lanka. Wildlife Heritage Trust of Sri Lanka.

Rahman, N.S. 1980. Hand book of food preservation. ( $2^{\text {nd }}$ edition): CRC Press, Taylor and Francis group.

Ratnasooriya, W.D., Lelwala, L.H.D.S., Kannangara, K.N.K. and Sandanayake, S.D.D. 2006. Sedative activity of steam bark of Sri Lankan Endemic Plant, Fitoterapia, 77: 331-332

Stone, H. and Sidel, J.L. 1985. Sensory evaluation practices. Academic Press, Orlando, USA.

Swaminathan, M. 1988. Hand book of food science and experimental foods. ( $1^{\text {st }}$ edition). The Bangalore Printing and Publishing Co. Ltd., Bangalore, India. 